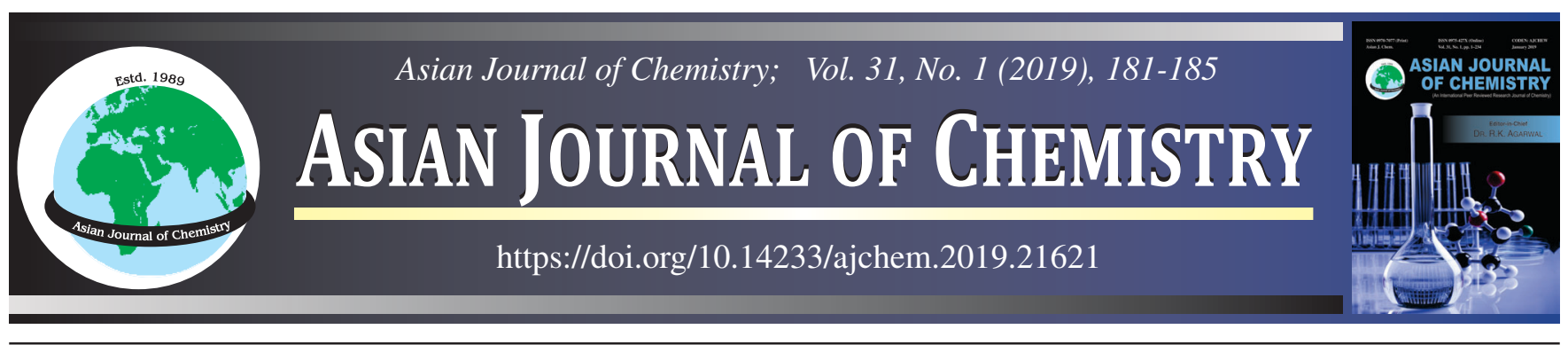

\title{
Synthesis, Characterization and Assessment of Local Anesthetic Activity of Some Benzohydroxamic Acids
}

Ekhlas Sheakh Aldeen ${ }^{1}$, Tilal Elsaman ${ }^{1,2, *}$, Malik Suliman Mohamed ${ }^{3,4}$, Mohamed E. Adam ${ }^{5}$ and Magdi Awadalla Mohamed ${ }^{2,5}$

${ }^{1}$ Department of Pharmaceutical Chemistry, College of Pharmacy, Omdurman Islamic University, Khartoum, Sudan

${ }^{2}$ Department of Pharmaceutical Chemistry, College of Pharmacy, Jouf University, Sakaka, Kingdom of Saudi Arabia

${ }^{3}$ Department of Pharmaceutics, College of Pharmacy, Jouf University, Sakaka, Kingdom of Saudi Arabia

${ }^{4}$ Department of Pharmaceutics, Faculty of Pharmacy, University of Khartoum, Khartoum, Sudan

${ }^{5}$ Department of Pharmaceutical Chemistry, Faculty of Pharmacy, University of Khartoum, Khartoum, Sudan

*Corresponding author: E-mail: telbashir@ju.edu.sa

In the present investigation, 6 compounds (E1-E6) were synthesized by reaction of ethyl esters of $p$-substituted benzoic acid with hydroxylamine. The chemical structures of the synthesized hydroxamic acids were verified on the basis of spectral analysis (IR, ${ }^{1} \mathrm{H}$ NMR, ${ }^{13} \mathrm{C}$ NMR and mass spectra). The benzohydroxamic acids were examined for potential local anesthetic activity using foot withdrawal reflex of the frog and benzocaine was used as standard drug. Compounds were tested at two different solvents; $5 \%$ DMSO and $0.65 \%$ $\mathrm{NaOH}$, each solution was tested at three different concentration levels $(40,100$ and $200 \mu \mathrm{g} / \mathrm{mL})$. Local anesthetic activity of the compounds differed according to the concentration level and selected solvent. Compounds $\mathbf{E} 4$ and $\mathbf{E} 5$ were found to be the most active and were comparable to the standard drug in tested solvents at all investigated concentrations. All compounds displayed an enhanced activity in the the aqueous basic solutions.

Keywords: Benzohydroxamic acids, Benzocaine, $p$-Substituted benzoic acid, Anesthetic activity.

ᄂ - - - - - - - - - - - - - - - - - - - - - - - - - - - -1

\section{INTRODUCTION}

Local anesthetics are widely used to abolish the sensation of pain associated with minor surgery when loss of consciousness is not desirable and to treat cancer related chronic pain. Local anesthetics block neural conduction by inhibiting sodium ions influx and exert their action by blocking nerve conductance after having bondage to selective site(s) of the Na-channels in the particular excitable membranes [1]. These drugs exert an anti-inflammatory effect, through interaction with G-protein receptors, and are thus used to prevent or treat pain [2]. What is evident is the focus since 1955 on the development of amino amide-linked and not amino ester-type local anesthetics; the reasons for this include the allergenicity of amino ester-type local anesthetics and the susceptibility of amino ester bonds for hydrolysis. The most clinical differences between esters and amides are that, ester linkage is more easily cleavable than the amide bond so the ester drugs are less stable in solution, with shorter duration of action and cannot be stored for as long as amides can. Amide anesthetics are also heatstable and can withstand autoclaving; esters cannot. The metabolism of most esters results in the production of $p$-aminobenzoate (PABA) which is associated with allergic reaction and antagonism for certain drugs such as sulphonamides. Amides-type local anesthetics, in contrast, rarely cause allergic phenomena. Nonetheless, they are associated with cardiotoxicity [3]. Hydroxamic acids are promising class of biologically active compounds which is a potential source for future development of new drug candidates.

Literature revealed only a few attempts to address new local anesthetics free from the aforementioned drawbacks. We have reported unprecedentedly the local anesthetic activity of benzohydroxamic acid [4]. In continuation with this, we synthesized and characterized six benzohydroxamic acid analogues E1-E6. The potential local anesthetic activity of these analogues was investigated and reported herein.

This is an open access journal, and articles are distributed under the terms of the Creative Commons Attribution-NonCommercial 4.0 International (CC BY-NC 4.0) License, which allows others to copy and redistribute the material in any medium or format, remix, transform, and build upon the material, as long as appropriate credit is given and the new creations are licensed under the identical terms. 


\section{EXPERIMENTAL}

All chemicals used were of commercially available reagent grade and were used without further purification. Melting points were determined on Electro thermal Karl Kolb (Scientific technical supplier Germany) and are uncorrected. Precoated silica gel plates, $\mathrm{GUV}_{254}$, obtained from SDFCL limited (India) were used for thin layer chromatography (TLC). Spots were visualized using UV-lamp at $254 \mathrm{~nm}$. Infrared spectra were recorded as $\mathrm{KBr}$ disk using SHIMADZU FT-IR apparatusJapan. NMR Spectra were determined in DMSO- $d_{6}$ and recorded on Bruker Avance III NMR Spectrophotometer (400 MHz) at the research center, College of Pharmacy, Ain Shams University, Egypt. Chemical shifts are expressed as $\delta$ values (ppm) relative to tetramethylsilane (TMS) as internal standard.

Mass spectra were done on Single ISQLT QuadrapoleMS spectrometer at the research center, College of Pharmacy, Azhar University, Egypt. Mass spectral data were given as $m / z$ (intensity \%). Ethical approval was obtained from Animal Ethics Committee, Department of Pharmacology, Faculty of Pharmacy Omdurman Islamic University, Khartoum, Sudan.

Synthesis of $\boldsymbol{p}$-substituted benzoic acids: Two of $p$-substituted benzoic acids namely, (methyl and methoxy derivatives) were prepared by oxidation of their corresponding aldehyde derivatives. Each sample $(0.01 \mathrm{~mol})$ was added to a solution of $0.02 \mathrm{~mol}$ of $\mathrm{KMnO}_{4}$ in $125 \mathrm{~mL}$ water at temperature less then $20^{\circ} \mathrm{C}$, then $3 \mathrm{M}$ of $\mathrm{NaOH}(1.5 \mathrm{~mL})$ was added and heated for $15 \mathrm{~min}$ at $40^{\circ} \mathrm{C}$ and boiled for $3 \mathrm{~min}$, the solution was filtered to remove magnesium dioxide, the filtrate was concentrated to one-fourth volume by heating, then conc. $\mathrm{HCl}$ was added until the media became acidic, further $5 \mathrm{~mL}$ of $\mathrm{HCl}$ were added, cooled at ice bath, solid products precipitated and filtered. Melting points were found to be 180 and $183{ }^{\circ} \mathrm{C}$ for $p$-methyl and p-methoxy benzoic acid (lit. $181^{\circ} \mathrm{C}$ and $185^{\circ} \mathrm{C}$, respectively [5].

Synthesis of ethyl $\boldsymbol{p}$-substituted benzoate: Esters of all derivatives were synthesized by the standard esterification method via Fischer esterification (McMurry, 2012) of corresponding p-substituted benzoic acids. The appropriate $p$-substituted benzoic acid $(0.1 \mathrm{~mol})$ was refluxed in $100 \mathrm{~mL}$ absolute ethanol and $14 \mathrm{~mL}$ conc. sulphuric acid. Completion of the reactions (2-8 h) was monitored by TLC using hexane:ethyl acetate as mobile phase. Solvent was evaporated and sodium bicarbonate solution was added until the solution became neutral, the resulted solution was subjected to extraction three times each of $20 \mathrm{~mL}$ dichloromethane. The extracts were collected and the solvent was evaporated, resulted esters were used in the second step without further purification, (m.p. ethyl $p$-amino and $p$-nitro benzoate were found to be $89^{\circ} \mathrm{C}$ and $58^{\circ} \mathrm{C}$ (lit. $88-90{ }^{\circ} \mathrm{C}$ and $55-59{ }^{\circ} \mathrm{C}$, respectively [6].

Compounds (E1-E6) were prepared using the general procedure [7] as follows:

Synthesis of $\boldsymbol{p}$-substituted potassium benzohydroxamate: Separate solutions of $4.67 \mathrm{~g}(0.067 \mathrm{~mol})$ of hydroxylamine hydrochloride in $240 \mathrm{~mL}$ of methyl alcohol and of $5.61 \mathrm{~g}$ $(0.1 \mathrm{~mol})$ of $\mathrm{KOH}$ in $140 \mathrm{~mL}$ of methyl alcohol were prepared at the boiling point of solvent. Both were cooled to $30-40{ }^{\circ} \mathrm{C}$ and the one containing alkali was added with shaking to hydroxylamine solution; any excessive rise of temperature during the addition was prevented by occasional cooling in an ice bath. After all the alkali has been added, the mixture was allowed to stand in an ice bath for five minutes to ensure complete precipitation of potassium chloride. Appropriate $p$-substituted ethyl benzoate $(5 \mathrm{~g}, 0.033 \mathrm{~mol})$ was added with thorough shaking and the mixture was filtered immediately with suction. The residue in the funnel was washed with a little methyl alcohol. The filtrate was placed in an Erlenmeyer flask and allowed to stand at room temperature. Crystals formed within $20 \mathrm{~min}$ to $3 \mathrm{~h}$ depending upon the amount of super saturation of the solution. After $48 \mathrm{~h}$, the crystals were filtered, washed with a little absolute ethyl alcohol and dried in air.

Synthesis of $\boldsymbol{p}$-substituted benzohydroxamic acid: A mixture of $3.5 \mathrm{~g}(0.02 \mathrm{~mol})$ of potassium salt in $16 \mathrm{~mL}$ of $1.25 \mathrm{~N}$ acetic acid stirred and heated until a clear solution was obtained. The solution was allowed to cool to room temperature and finally cooled in an ice bath. The target compounds precipitated as crystals, filtered, dried and the purity of the product was checked using TLC.

Benzohydroxamic acid (E1): White crystals, m.f.: $\mathrm{C}_{7} \mathrm{H}_{7} \mathrm{NO}_{2}$, yield: $75 \%$, m.p. $126^{\circ} \mathrm{C}, \mathrm{Clog}$ P: 1.11. IR (KBr, $\left.v_{\max }, \mathrm{cm}^{-1}\right): 3292$ (-OH str., br), 3055 (Ar-H str.), 1629 (C=O str., s); 1560 and 1409 (arom. $\mathrm{C}=\mathrm{C}$ str. $).{ }^{1} \mathrm{H}$ NMR: $\left(\delta \mathrm{ppm}, \mathrm{DMSO}-d_{6}\right): 7.4-7.8(5 \mathrm{H}, \mathrm{Ar}-$ $\boldsymbol{H})$; 9 br $(1 \mathrm{H}, \mathrm{NH}) ; 11.2$ br $(1 \mathrm{H},-\mathrm{OH}) .{ }^{13} \mathrm{C} \mathrm{NMR}:(\delta \mathrm{ppm}, \mathrm{DMSO}-$ $\left.d_{6}\right)$ : $127.34,128.83,131.59,133.25(\mathrm{Ar}-\boldsymbol{C})$; $164.79(\boldsymbol{C}=\mathrm{O})$. EIMS: $m / z$ (rel. int): $137[\mathrm{M}]^{+}(5 \%) ; 136(11 \%) ; 119(15 \%) ; 108$ (10.5\%); 93 (96\%); 92 (21\%); 91 (27\%); 77 (100\%); 66 (20 $\%) ; 65$ (17\%); 64 (14\%); 51(12.9\%); 48 (46\%); 44 (43\%).

p-Aminobenzohydroxamic acid (E2): Pale brown crystals, m.f.: $\mathrm{C}_{7} \mathrm{H}_{8} \mathrm{~N}_{2} \mathrm{O}_{2}$, yield: $73 \%$, m.p. $185^{\circ} \mathrm{C}, \mathrm{Clog}$ P: 0.30. IR ( $\mathrm{KBr}$, $v_{\max }, \mathrm{cm}^{-1}$ ): 3255 (-OH str., br), 3072(Ar-H str.); 1609 (C=O str., s); 1478 and 1534 (arom. $\mathrm{C}=\mathrm{C}$ str.). ${ }^{1} \mathrm{H}$ NMR: $(\delta$ ppm, DMSO$\left.d_{6}\right)$ : 5.6 br $\left(2 \mathrm{H}, \mathrm{Ar}-\mathrm{NH}_{2}\right)$; 6.5-7.5 (4H, Ar-H); 8.69 (1H, NH); $10.77(1 \mathrm{H},-\mathrm{OH}) .{ }^{13} \mathrm{C}$ NMR: $\left(\delta \mathrm{ppm}, \mathrm{DMSO}-d_{6}\right): 113.14,119.66$, 128.82, $152.10(\mathrm{Ar}-\boldsymbol{C}) ; 165.61(\boldsymbol{C}=\mathrm{O})$. EI-MS: $m / z$ (rel. int): 152 $[\mathrm{M}]^{+}(16.8 \%) ; 120(100 \%) ; 92(38 \%) ; 65(20 \%)$.

p-Nitrobenzohydroxamic acid (E3): Pale yellow powder, m.f.: $\mathrm{C}_{7} \mathrm{H}_{6} \mathrm{~N}_{2} \mathrm{O}_{4}$, yield: $51 \%$, m.p. $180{ }^{\circ} \mathrm{C}$, Clog P: 0.43. IR $\left(\mathrm{KBr}, v_{\max }, \mathrm{cm}^{-1}\right.$ ): 3258 (-OH str., br), 3114 (Ar-H str.), 1665 $(\mathrm{C}=\mathrm{O}$ str., s), 1506 and 1433 (arom. $\mathrm{C}=\mathrm{C}$ str.), 1515 and 1352 $\left(\mathrm{NO}_{2}\right.$ str., s). ${ }^{1} \mathrm{H}$ NMR: ( $\delta$ ppm, DMSO- $\left.d_{6}\right)$ : 7.95-8.5 (4H, Ar$\boldsymbol{H}) ; 9.58(1 \mathrm{H}, \mathrm{NH}) ; 11.57(1 \mathrm{H},-\mathrm{OH}) .{ }^{13} \mathrm{C} \mathrm{NMR}$ : $(\delta \mathrm{ppm}, \mathrm{DMSO}-$ $\left.d_{6}\right)$ : $124.07,128.83,131.09,135.87(\mathrm{Ar}-\boldsymbol{C}) ; 165.09$ ( $\left.\boldsymbol{C}=\mathrm{O}\right)$. EIMS: $m / z$ (rel. int): $182[\mathrm{M}]^{+}(12.8 \%) ; 150(100 \%) ; 138(21$ $\%), 120$ (14.8\%); 108 (15.8\%); 104 (54.5\%); 92 (32.8\%); $76(32.6 \%)$; 65 (22\%); 50 (14.5\%); 44(22\%); 40 (54\%).

p-Methylbenzohydroxamic acid (E4): White powder, m.f.: $\mathrm{C}_{8} \mathrm{H}_{9} \mathrm{NO}_{2}$, yield: $46 \%$, m.p. $150{ }^{\circ} \mathrm{C}, \mathrm{Clog} \mathrm{P}: 1.59$. IR (KBr, $v_{\max }$, $\mathrm{cm}^{-1}$ ): 3426 (-OH str., br), 3052 (Ar-H str.), 1646 (C=O str., s); 1612 and 1417 (arom. C=C str.); 2917 (aliph. C-H str.). ${ }^{1} \mathrm{H}$ NMR: $\left(\delta\right.$ ppm, DMSO- $\left.d_{6}\right):$ 7.2-7.75 $(4 \mathrm{H}, \mathrm{Ar}-\boldsymbol{H}), 9.44(1 \mathrm{H}$, $\mathrm{NH}), 10.84(1 \mathrm{H},-\mathrm{OH}), 2.3\left(3 \mathrm{H},-\mathrm{CH}_{3}\right) .{ }^{13} \mathrm{C} \mathrm{NMR}:(\delta \mathrm{ppm}$, DMSO-d $)$ : $21.41\left(-\mathrm{CH}_{3}\right), 127.3,129.34,130.48,141.40(\mathrm{Ar}-$ $\boldsymbol{C}) ; 164.5(\boldsymbol{C}=\mathrm{O})$. EI-MS: $m / z$ (rel. int): $151[\mathrm{M}]^{+}(2.6 \%)$; 119.08 (39.6\%); 107 (80\%); 106(100\%); 91(31.7\%); 79 (13\%); 77(18\%); 44 (34\%); 40(94\%).

p-Methoxybenzohydroxamic acid (E5): White powder, m.f.: $\mathrm{C}_{8} \mathrm{H}_{9} \mathrm{NO}_{3}$, yield: $71 \%$, m.p. $159^{\circ} \mathrm{C}, \mathrm{Clog}$ P: 0.90. IR (KBr, 
$\left.v_{\max }, \mathrm{cm}^{-1}\right): 3284$ (-OH str., br), 3028 (Ar-H str.), $1604(\mathrm{C}=\mathrm{O}$ str., s); 1508 and 1427 (arom. $\mathrm{C}=\mathrm{C}$ str.); 1255 and $1024\left(\mathrm{C}-\mathrm{O}\right.$ str. $-\mathrm{OCH}_{3}$ ), ${ }^{1} \mathrm{H} N M R:\left(\delta \mathrm{ppm}, \mathrm{DMSO}-d_{6}\right): 3.8\left(3 \mathrm{H},-\mathrm{OCH}_{3}\right) ; 6.9-7.1(4 \mathrm{H}, \mathrm{Ar}-$ $\boldsymbol{H})$; 7.5-8.0 (4H, Ar- $\boldsymbol{H}) ; 11.11(1 \mathrm{H},-\mathrm{OH})\left(\mathrm{D}_{2} \mathrm{O}\right.$ exchangeable). ${ }^{13} \mathrm{C}$ NMR: $\left(\delta \mathrm{ppm}, \mathrm{DMSO}-d_{6}\right): 55.77,55.85\left(-\mathrm{OCH}_{3}\right), 114.07$, 125.49, 129.08, $131.72(\mathrm{Ar}-\mathrm{C})$; $164(\mathrm{C}=\mathrm{O})$. EI-MS: $m / z$ (rel. int): 167[M] $]^{+}(8 \%), 135$ (100\%) 107 (14.7\%), 92 (16\%), 77 (24\%).

p-Chlorobenzohydroxamic acid (E6): White crystals, m.f.: $\mathrm{C}_{7} \mathrm{H}_{6} \mathrm{NO}_{2} \mathrm{Cl}$, yield: $68 \%$, m.p. $180{ }^{\circ} \mathrm{C}$, Clog P: 1.67. IR (KBr, $\left.v_{\max }, \mathrm{cm}^{-1}\right)$ : 3281 (-OH str., br), 3094 (Ar-H str.); 1680 (C=O str., s); 1592 and 1491 (arom. C=C str.); 1093 (C-Cl str.). ${ }^{1} \mathrm{H}$ NMR: $\left(\delta\right.$ ppm, DMSO- $\left.d_{6}\right)$ : 7.4-7.6 (4H, Ar- $\left.\boldsymbol{H}\right) ; 7.7-8(4 \mathrm{H}, \mathrm{Ar}-\boldsymbol{H}) ; 9.23$ $(1 \mathrm{H}, \mathrm{NH}) ; 11.3(1 \mathrm{H},-\mathrm{OH}) .{ }^{13} \mathrm{CNMR}:\left(\delta \mathrm{ppm}, \mathrm{DMSO}-d_{6}\right): 129.20$, 130.21, 131.16, $138.22(\mathrm{Ar}-\boldsymbol{C})$; $166.9(\boldsymbol{C}=\mathrm{O})$. EI-MS: $m / z$ (rel. int): $171[\mathrm{M}]^{+}(1.15 \%), 139(19 \%), 129(33 \%), 128(10 \%), 127$ (100\%), $111(16 \%), 99(10 \%), 44(25 \%), 40(85 \%)$.

Anesthetic activity (foot withdrawal reflex of frog): A frog was killed by stunning and decapitating the head. The viscera were removed from the abdominal pouch with fine forceps with care not to damage the nerves at the base of spinal cord. The frog was spinned by its front limbs to a vertically mounted cork board so that the hind legs were suspended freely below it. Both hind limbs dipped into a beaker containing $0.05 \mathrm{M}$ $\mathrm{HCl}$ and time taken for the frog to withdraw the feet was noted, legs were washed with $0.9 \%$ normal saline after feet withdrawal reflex [4]. Different concentration levels of $\mathrm{HCl}$ were used $(0.05 \mathrm{M}, 0.1 \mathrm{M}$ and $0.2 \mathrm{M})$ and each frog was tested for withdrawal reflex using different concentration levels of $\mathrm{HCl}$ to elicit the response. The time taken for the frog to withdraw the foot was recorded and considered as the control. Those, which did not respond to $0.2 \mathrm{MHCl}$ after $10 \mathrm{~s}$ contact were excluded from the experiment. Three concentration levels (1000, 200 and $40 \mu \mathrm{g} / \mathrm{mL}$ ) were prepared for all tested compounds and for benzocaine as standard drug. The synthesized compounds were tested in two different solvents $(0.65 \%$ of $0.1 \mathrm{~N} \mathrm{NaOH}$ and $5 \%$ aqueous DMSO). Benzocaine was dissolved only in $5 \%$ DMSO (insoluble in $0.65 \% \mathrm{NaOH}$ ) and compound $\mathbf{E 6}$ only in $0.65 \% \mathrm{NaOH}$ since it was found insoluble in $5 \%$ DMSO. Thirty seven groups each of four frogs were used in this study; each tested concentration for the titled compounds and the standard drug required one group beside the negative control groups. The results were analyzed statistically using prism-5 software.

\section{RESULTS AND DISCUSSION}

The reaction for the preparation of compounds is depicted in Scheme-I. Synthesis was initiated by reacting appropriate $p$-substituted benzoic acid ester to equimolar amount of hydroxylamine. Potassium hydroxide was used to liberate hydroxylamine from its hydrochloride salt. Due to the presence of the base the products were obtained as potassium salts, acidification with acetic acid furnished the target compounds E1-E6 [8].

Melting points of the synthesized hydroxamic acids were higher when compared to corresponding esters. TLC plates for compounds $\mathbf{E 5}$ and E6 showed two spots rather than one and this can be explained by the existence of two tautomeric forms ( $E$ - and $Z$-) of these compounds in solution. All prepared

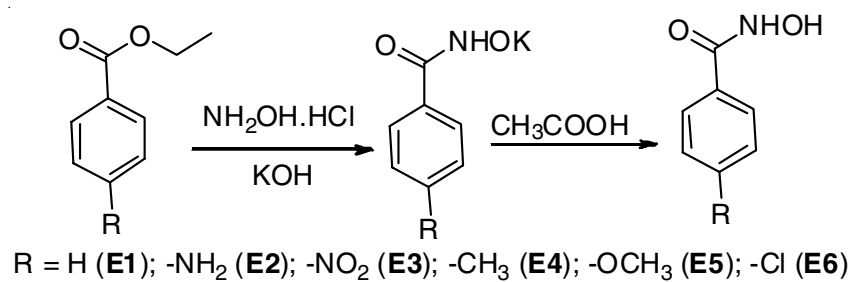

Scheme-I: Synthesis of compounds E1-E6

compounds displayed characteristic violet colour with ferric chloride. IR spectra showed a broad band at $3450-3200 \mathrm{~cm}^{-1}$ due to -OH group stretching, sharp and strong band at 1680$1600 \mathrm{~cm}^{-1}$ that characterized the $\mathrm{C}=\mathrm{O}$ stretching $[9,10]$. Medium band at $3115-3000 \mathrm{~cm}^{-1}$ can be ascribed to aromatic C-H stretching, aromatic $\mathrm{C}=\mathrm{C}$ stretching around $1600-1400 \mathrm{~cm}^{-1}$, bands at $950-900$ and $1440-1300 \mathrm{~cm}^{-1}$ were assigned for $\mathrm{N}-\mathrm{O}$ and $\mathrm{C}-\mathrm{N}$ stretching, respectively. These results were found to be in consistence with that previously reported in the literature [11]. On the other hand, ${ }^{1} \mathrm{H}$ NMR spectra of hydroxamic acids showed the characteristic $\mathrm{D}_{2} \mathrm{O}$ exchangeable broad singlet signal of -OH proton in the region 10.5-11.5 ppm, shifting of the resonance signal of this proton to lower field supported intermolecular hydrogen bonding. Moreover, each compound exhibited signals of the aromatic protons at 6.5-8.5 ppm. ${ }^{13} \mathrm{C}$ NMR spectra exhibited absorption signal due to carbonyl, $\mathrm{C}=\mathrm{O}$ carbon nearby $165 \mathrm{ppm}$, all synthesized compounds showed this signals which was consistent with that reported in literature [7]. On the other hand, signals of Ar-C of these compounds displayed at 114$152 \mathrm{ppm}$ and the signals number was consistent with the number of non-equivalent carbons in each compound.

Anesthetic activity: The local anesthetic activities of the synthesized compounds in $5 \%$ DMSO are depicted in Table-1 and from the obtained results, it was obvious that most of the prepared compounds displayed excellent to modest local anesthetic activity. In particular, compounds $\mathbf{E} \mathbf{4}$ and $\mathbf{E 5}$ were found to be the most potent counterparts at the tested three doses and showed no significant differences from the standard benzocaine at the same dose levels as shown in Figs. 1 and 2. On the other hand, the least effective compounds were $\mathbf{E} \mathbf{1}$ and $\mathbf{E} 3$ at all tested doses.

TABLE-1

LOCAL ANESTHETIC ACTIVITY OF THE SYNTHESIZED COMPOUNDS IN $5 \%$ DMSO COMPARED TO BENZOCAINE

\begin{tabular}{cccccc}
\hline \multirow{2}{*}{ Compd. } & $\begin{array}{c}\text { Dose } \\
(\mu \mathrm{g} / \mathrm{mL})\end{array}$ & $\begin{array}{c}\text { Mean } \pm \\
\text { SEM }(\mathrm{s})\end{array}$ & $\begin{array}{c}\text { STD } \\
(\text { Benzocaine })\end{array}$ & $\begin{array}{c}\text { Mean } \pm \\
\text { SEM }(\mathrm{s})\end{array}$ & P-value \\
\hline \multirow{3}{*}{ E1 } & 1000 & $0.25 \pm 0.25$ & 1000 & $8.00 \pm 1.00$ & 0.0003 \\
& 200 & $0.50 \pm 0.30$ & 200 & $7.00 \pm 2.00$ & 0.0100 \\
& 40 & $1.70 \pm 0.80$ & 40 & $8.75 \pm 0.25$ & 0.0002 \\
\hline \multirow{3}{*}{ E2 } & 1000 & $0.00 \pm 0.90$ & 1000 & $8.00 \pm 1.00$ & 0.0020 \\
& 200 & $5.70 \pm 1.90$ & 200 & $7.00 \pm 2.00$ & 0.7000 \\
& 40 & $1.20 \pm 0.75$ & 40 & $8.75 \pm 0.25$ & 0.0001 \\
\hline \multirow{3}{*}{ E3 } & 1000 & $3.75 \pm 0.75$ & 1000 & $8.00 \pm 1.00$ & 0.0200 \\
& 200 & $1.50 \pm 0.90$ & 200 & $7.00 \pm 2.00$ & 0.0400 \\
& 40 & $3.00 \pm 2.04$ & 40 & $8.75 \pm 0.25$ & 0.0300 \\
\hline \multirow{3}{*}{ E4 } & 1000 & $7.50 \pm 1.50$ & 1000 & $8.00 \pm 1.00$ & 0.8000 \\
& 200 & $7.20 \pm 1.00$ & 200 & $7.00 \pm 2.00$ & 0.9000 \\
& 40 & $6.20 \pm 1.60$ & 40 & $8.75 \pm 0.25$ & 0.2000 \\
\hline \multirow{2}{*}{ E5 } & 1000 & $6.70 \pm 1.70$ & 1000 & $8.00 \pm 1.00$ & 0.6000 \\
& 200 & $8.00 \pm 1.00$ & 200 & $7.00 \pm 2.00$ & 0.7000 \\
& 40 & $6.20 \pm 2.00$ & 40 & $8.75 \pm 0.25$ & 0.3000 \\
\hline
\end{tabular}




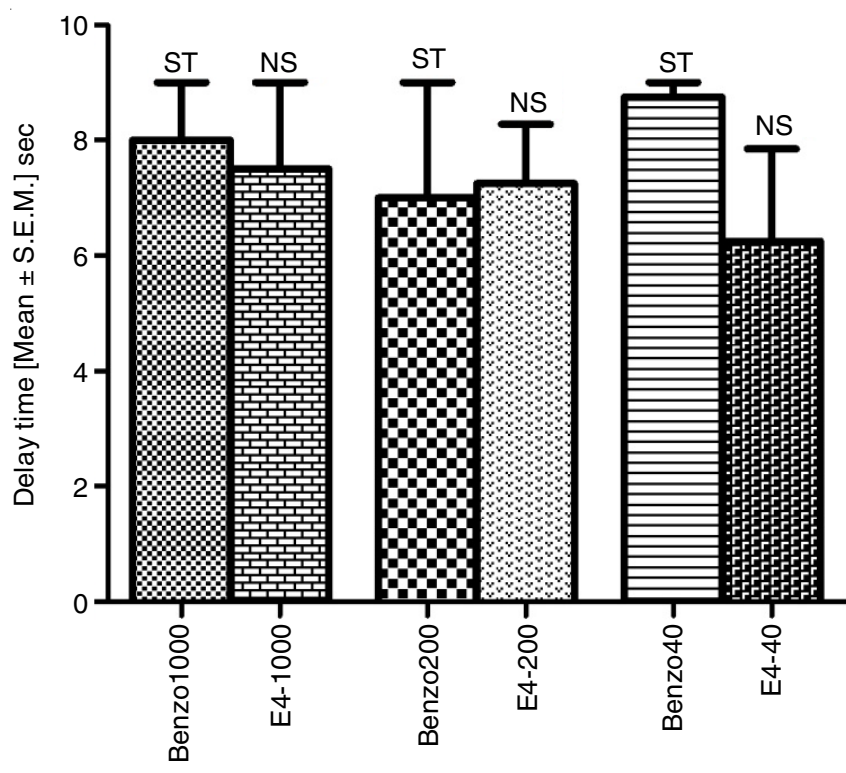

Fig. 1. Local anesthetic activity of compound $\mathbf{E 4}$ in 5\% DMSO

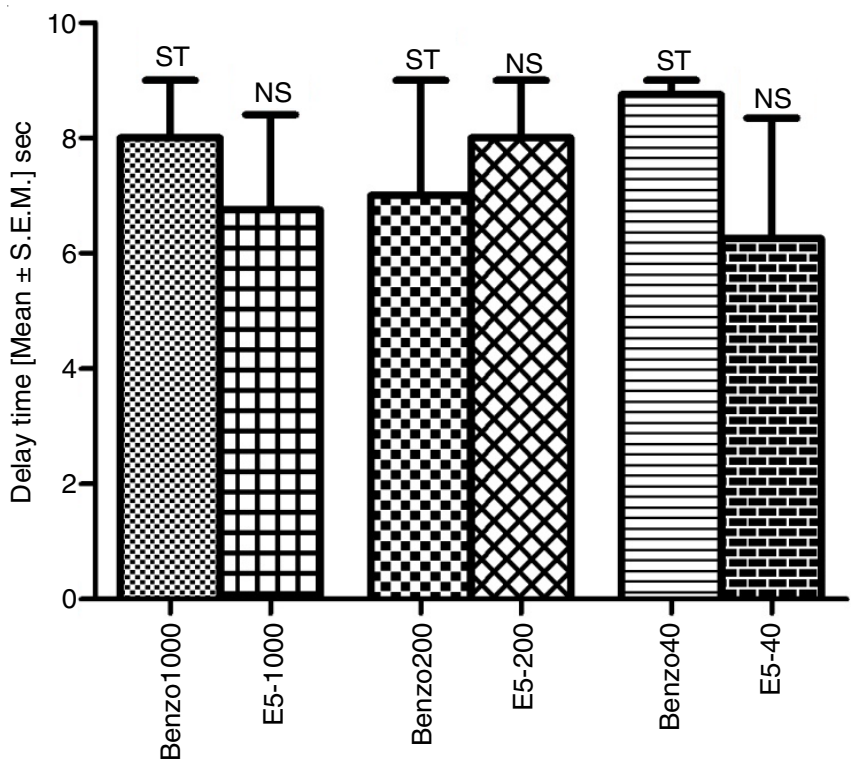

Fig. 2. Local anesthetic activity of compound E5 in $5 \%$ DMSO

The activity of compounds $\mathbf{E} \mathbf{4}$ and $\mathbf{E 5}$ most probably due to the strong electron donating properties of methyl and methoxy groups located in para position, respectively. This was found to be consistent with that reported in literature, since electrondonating substituent in ortho and/or para positions increases local anesthetic potency of the conventional local anesthetics. Besides, the local anesthetic activities of these compounds were investigated in aqueous $0.65 \% \mathrm{NaOH}$ solution (as sodium salt) and benzocaine was also used as drug standard as displayed in Table-2.

Compounds $\mathbf{E} 4$ and $\mathbf{E 5}$ possessed excellent local anesthetic activities when used as sodium salts (in $0.65 \% \mathrm{NaOH}$ ) compared to aqueous $5 \%$ DMSO and this can be explained in part by the significant contribution of the newly formed ionic bond. Compound $\mathbf{E} 4$ sodium salt was found to be most effective at three doses and showed no significant difference with the standard drug as explained in Fig. 3. However, compound $\mathbf{E 5}$ sodium salt showed no significant differences with standard
TABLE-2

LOCAL ANESTHETIC ACTIVITY OF THE

SYNTHESIZED COMPOUNDS IN $0.65 \% \mathrm{NAOH}$ SOLUTION COMPARED TO BENZOCAINE

\begin{tabular}{cccccc}
\hline $\begin{array}{c}\text { Compd. } \\
\text { as Na } \\
\text { salt }\end{array}$ & $\begin{array}{c}\text { Dose } \\
(\mu \mathrm{g} / \mathrm{mL})\end{array}$ & $\begin{array}{c}\text { Mean } \pm \\
\text { SEM }(\mathrm{s})\end{array}$ & $\begin{array}{c}\text { STD } \\
(\text { Benzocaine })\end{array}$ & $\begin{array}{c}\text { Mean } \pm \\
\text { SEM }(\mathrm{s})\end{array}$ & P-value \\
\hline \multirow{3}{*}{ E1 } & 1000 & $3.20 \pm 1.90$ & 1000 & $8.00 \pm 1.00$ & 0.1000 \\
& 200 & $1.00 \pm 0.40$ & 200 & $7.00 \pm 2.00$ & 0.0300 \\
& 40 & $3.20 \pm 1.30$ & 40 & $8.75 \pm 0.25$ & 0.0060 \\
\hline \multirow{3}{*}{$\mathbf{E 2}$} & 1000 & $3.20 \pm 2.10$ & 1000 & $8.00 \pm 1.00$ & 0.1300 \\
& 200 & $6.20 \pm 1.60$ & 200 & $7.00 \pm 2.00$ & 0.8000 \\
& 40 & $7.20 \pm 1.10$ & 40 & $8.75 \pm 0.25$ & 0.3000 \\
\hline \multirow{2}{*}{$\mathbf{E 3}$} & 1000 & $8.50 \pm 0.50$ & 1000 & $8.00 \pm 1.00$ & 0.6000 \\
& 200 & $8.00 \pm 0.60$ & 200 & $7.00 \pm 2.00$ & 0.6000 \\
& 40 & $7.00 \pm 1.60$ & 40 & $8.75 \pm 0.25$ & 0.3000 \\
\hline & 1000 & $7.25 \pm 1.40$ & 1000 & $8.00 \pm 1.00$ & 0.7000 \\
$\mathbf{E 4}$ & 200 & $5.50 \pm 1.90$ & 200 & $7.00 \pm 2.00$ & 0.6000 \\
& 40 & $6.75 \pm 2.20$ & 40 & $8.75 \pm 0.25$ & 0.9000 \\
\hline & 1000 & $8.50 \pm 0.28$ & 1000 & $8.00 \pm 1.00$ & 0.6000 \\
$\mathbf{E 5}$ & 200 & $6.70 \pm 2.20$ & 200 & $7.00 \pm 2.00$ & 0.9000 \\
& 40 & $2.20 \pm 0.80$ & 40 & $8.75 \pm 0.25$ & 0.0003 \\
\hline \multirow{2}{*}{$\mathbf{E 6}$} & 1000 & $6.70 \pm 1.90$ & 1000 & $8.00 \pm 1.00$ & 0.6000 \\
& 200 & $6.50 \pm 2.10$ & 200 & $7.00 \pm 2.00$ & 0.8000 \\
& 40 & $7.00 \pm 1.60$ & 40 & $8.75 \pm 0.25$ & 0.3000 \\
\hline
\end{tabular}

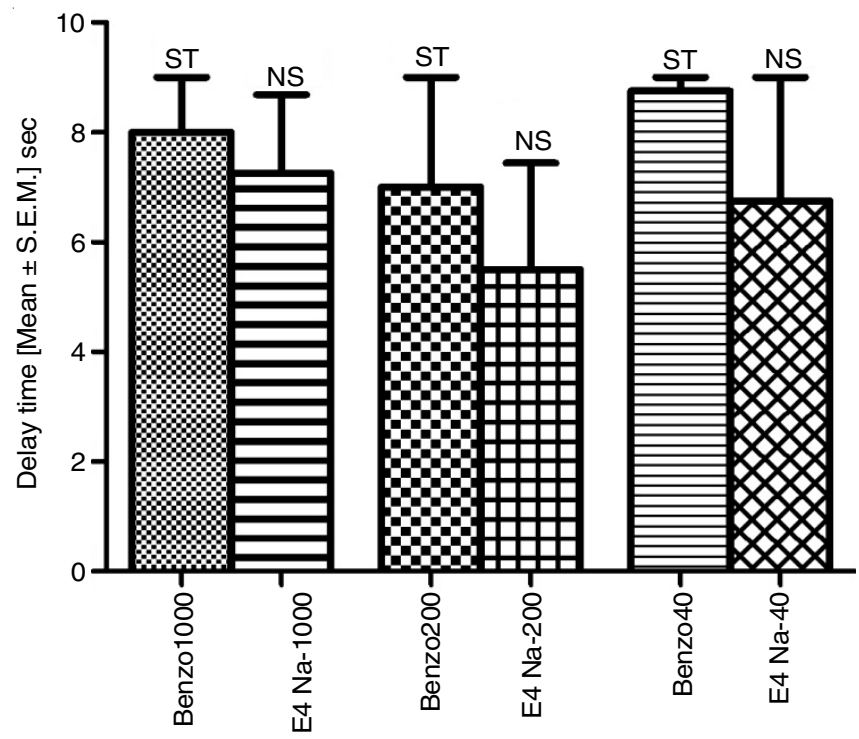

Fig. 3. Local anesthetic activity of compound $\mathbf{E} 4$ sodium salt

except at a dose of $40 \mu \mathrm{g} / \mathrm{mL}$ as revealed in Fig. 4. Moreover, compounds $\mathbf{E} \mathbf{4}$ and $\mathbf{E 5}$ when tested as sodium salts exhibited superior activity when compared to the reported compound $\mathbf{E 2}$ sodium salt [4]. On the other hand, compound E1 as sodium salt displayed no improvement in activity, suggesting the significance of para-substitution over the ionic bond interaction. In contrast to the weak activity observed for compound $\mathbf{E 3}$ when tested in $5 \%$ DMSO at all dose levels, significant activity was documented for this compound when tested in aqueous basic solution compared to the standard drug at all tested doses. This enhancement in activity could be explained in part either by the contribution of newly involved ionic bond or the uniqueness of mechanism of action of this compound since this compound incorporates $-\mathrm{NO}_{2}$ group (a strong electron withdrawing substituent) located in para-position. Compound E6, which was tested only as sodium salt, exhibited an enhanced activity over that of the standard drug benzocaine at all tested doses. 


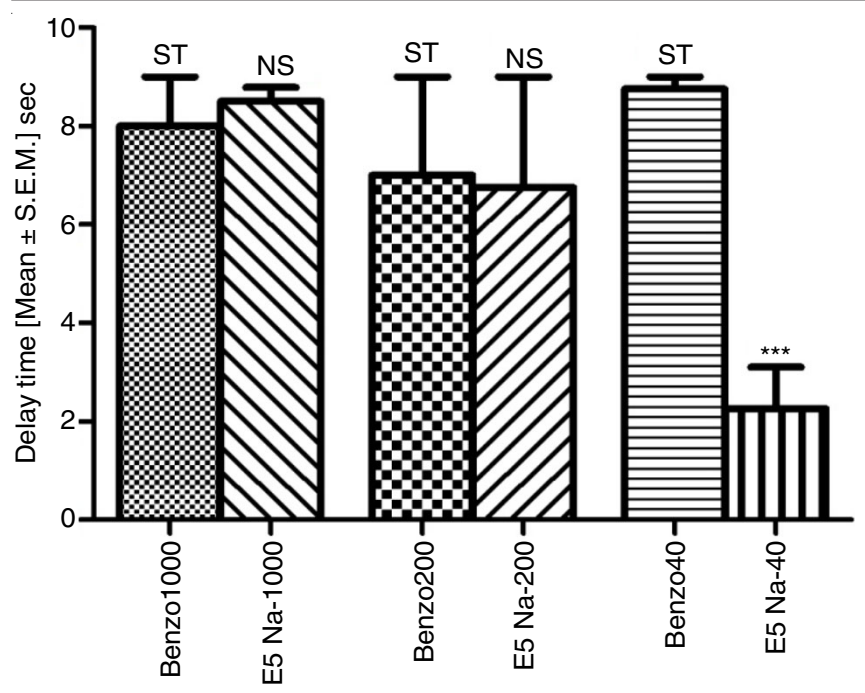

Fig. 4. Local anesthetic activity of compound $\mathbf{E 5}$ sodium salt

\section{Conclusion}

In summary, six benzohydroxamic acids (E1-E6) were synthesized, characterized by various spectral techniques and investigated as free acids and as sodium salts for local anesthetic activity. Of these derivatives, compounds $\mathbf{E 4}$ and $\mathbf{E 5}$ emerged as the most active members and were comparable to the standard drug (benzocaine) at all tested concentrations in the two selected solvents. Furthermore, the titled compounds have potential advantages over the conventional local anesthetic viz., (a) comparable activity, (b) can be easily formulated in water, (c) heat stable, (d) not susceptible to hydrolyzing enzymes (long duration), (e) free from allergenic potential as they don't release para-aminobenzoate (PABA) and (f) free from clinical antagonism of certain drugs.

\section{CONFLICT OF INTEREST}

The authors declare that there is no conflict of interests regarding the publication of this article.

\section{REFERENCES}

1. D.E. Becker and K.L. Reed, Anesth. Prog., 53, 98 (2006); https://doi.org/10.2344/0003-3006(2006)53[98:EOLAP]2.0.CO;2.

2. M.W. Hollmann, S. Herroeder, K.S. Kurz, C.W. Hoenemann, D. Struemper, K. Hahnenkamp and M.E. Durieux, Am. Soc. Anesthesiol., 100, 852 (2004);

https://doi.org/10.1097/00000542-200404000-00015.

3. J.E. Heavner, Curr. Opin. Anaesthesiol., 20, 336 (2007); https://doi.org/10.1097/ACO.0b013e3281c10a08.

4. M.A. Magdi, M.E.M. Mahmoud and A. A. Abdalla, Int. J. Pharm. Res. Bio-Sci., 3, 132 (2014).

5. S.J. Gorzynski, Organic Chemistry, McGraw-Hill: New York (2011).

6. F.A. Carey and R.J. Sundberg. Advanced Organic Chemistry, Springer Science+Business Media: New York, p. 721 (2007).

7. R.C. Hauser and W.B. Renfrow, Org. Synth., 19, 15 (1939); https://doi.org/10.15227/orgsyn.019.0015.

8. D.L. Pavia, G.M. Lampman, G.S. Kriz and J.R. Vyvyan, Introduction to Spectroscopy, Cengage Learning: Belmont, Canada, p. 52 (2008).

9. H. Agarwal, O.P. Agarwal, R. Karnawat, K.I. Sharma and P.S. Verma, Int. J. Appl. Biol. Pharm. Technol., 1, 1293 (2010).

10. R.M. Robe, J.C. Gilberf, L.B. Rodewald and A.S. Wingrove, Modern Experimental Organic Chemistry, Saunders College: Philadelphia, USA, p. 621 (1979).

11. J. McMurry. Organic chemistry, Cengage Learning: Belmont, Canada, p. 424 (2012). 